This item was submitted to Loughborough's Research Repository by the author.

Items in Figshare are protected by copyright, with all rights reserved, unless otherwise indicated.

\title{
The effect of nozzle geometry on the flow characteristics of small water jets
}

PLEASE CITE THE PUBLISHED VERSION

PUBLISHER

(C) Professional Engineering Publishing

VERSION

VoR (Version of Record)

LICENCE

CC BY-NC-ND 4.0

REPOSITORY RECORD

Ghassemieh, E., Hendrik K. Versteeg, and Memis Acar. 2019. "The Effect of Nozzle Geometry on the Flow Characteristics of Small Water Jets”. figshare. https://hdl.handle.net/2134/4518. 
This item was submitted to Loughborough's Institutional Repository (https://dspace.lboro.ac.uk/) by the author and is made available under the following Creative Commons Licence conditions.

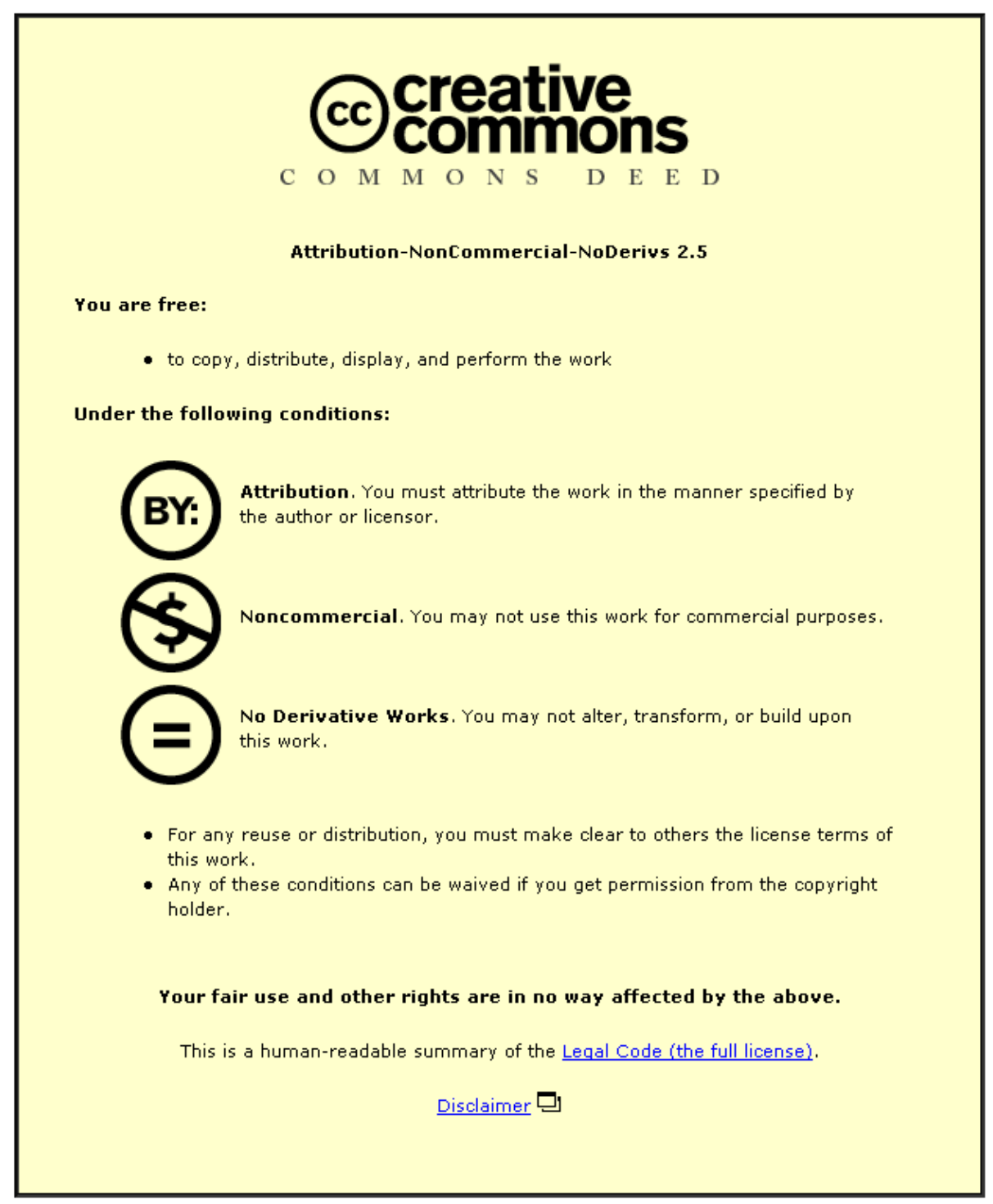

For the full text of this licence, please go to: http://creativecommons.org/licenses/by-nc-nd/2.5/ 


\title{
The effect of nozzle geometry on the flow characteristics of small water jets
}

\author{
E Ghassemieh $^{1}$, H K Versteeg ${ }^{2 *}$, and M Acar $^{2}$ \\ ${ }^{1}$ Department of Mechanical Engineering, University of Sheffield, Sheffield, UK \\ ${ }^{2}$ Wolfson School of Mechanical and Manufacturing Engineering, Loughborough University, Loughborough, \\ Leicestershire, UK
}

The manuscript was received on 30 June 2006 and was accepted after revision for publication on 4 September 2006.

DOI: 10.1243/0954406JMES430

\begin{abstract}
A wide variety of processes make use of plain orifice nozzles. Fuel injectors for internal combustion engines incorporate these nozzles to generate finely atomized sprays. Processes such as jet cutting, jet cleaning, and hydroentanglement, on the other hand, use similar nozzles, but require coherent jets. The spray or jet characteristics depend on the stability of the flow emerging from the orifice. This problem has been extensively researched for nozzles with diameters above $300 \mu \mathrm{m}$. Much less is known about the characteristics of jets produced by nozzles with smaller diameters, where viscous effects and small geometric variations due to manufacturing tolerances are likely to play an increasing role. Results are presented of a wide-ranging investigation of geometry effects on the flow parameters and jet characteristics of nozzles with diameters between 120 and $170 \mu \mathrm{m}$. Nozzles with circular cross-section and conical, cone-capillary and capillary axial designs were investigated. For conical and conecapillary nozzles, the effect of cone angle and effects due to interactions between adjacent nozzles in the multi-hole cone-capillary nozzles were studied. For capillary nozzles, the effects of diameter variations and inlet edge roundness for capillary nozzles were considered. Furthermore, the effect of varying the aspect ratio (ratio of major and minor axes) of elliptical nozzles was studied. Flowrate and jet impact force measurements were carried out to determine the discharge coefficient $C_{\mathrm{d}}$, velocity coefficient $C_{\mathrm{v}}$, and contraction coefficient $C_{\mathrm{c}}$ of the nozzles for supply pressures between 3 and $12 \mathrm{MPa}$. Visualizations of the jet flow were carried out in the vicinity of the nozzle exit in order to identify near-nozzle flow regimes and to study jet coherence. The relationship between nozzle geometry, discharge characteristics, and jet coherence is examined.
\end{abstract}

Keywords: fluid flow, water jets, small nozzles, nozzle geometry, discharge characteristics, manufacturing flaws

\section{INTRODUCTION}

Much of our understanding of the relationship between nozzle geometry and liquid jet properties relates to engine injectors. Early work by Bergwerk [1] reports measurements of the discharge coefficient $C_{\mathrm{d}}$ and visual observations using transparent cylindrical nozzles with sharp and chamfered inlets and

*Corresponding author: Wolfson School of Manufacturing, and Mechanical Engineering, University of Loughborough, Loughborough, Leicestershire LE11 3TU, UK. email: h.k.versteeg@ lboro.ac.uk diameter ranging between 0.2 and $0.5 \mathrm{~mm}$. Reitz and Bracco [2] reported the first wide-ranging investigation of nozzle geometry effects covering cylindrical orifices with square and rounded inlet edges as well as conical and smoothly curved converging nozzles. The work was focused on the fluid mechanics of jet break-up and atomization and concluded that the effects of geometry on atomization were attributable to one or more of the following candidate mechanisms: (a) cavitation, (b) turbulence, (c) velocity profile effects, (d) nozzle boundary layer effects, (e) aerodynamic effects due to interaction of the emerging liquid jet with ambient gas, and 
(f) manufacturing imperfections. Wu et al. [3] also considered conical nozzles with a $90^{\circ}$ contraction and a $40^{\circ}$ divergence and studied the effects of inlet flow conditions. Arai et al. $[\mathbf{4}, \mathbf{5}]$ and Hiroyasu et al. [6] compared capillary tubes with sharp and rounded inlets. Ohrn et al. [7] studied the effect of inlet edge roundness and conical chamfer on the discharge coefficients. Karasawa et al. [8] performed a systematic comparison of capillary tubes with diameter around $300 \mu \mathrm{m}$ with sharp and rounded inlet edges over a range of length to diameter $L / D$ ratio between 1 and 50 and also tested an orifice with a $60^{\circ}$ inlet chamfer. Because of its application to engine injectors, this research has primarily concentrated on nozzles with diameters $\geq 300 \mu \mathrm{m}$ and on atomization.

Coherent jets have been widely used in jet cutting and cleaning applications and there has been a recent resurgence of interest in nozzles generating this type flow after the commercialization of hydroentanglement, a non-woven textile production process [9]. In this process, a loose web of randomly oriented fibres is supplied on a porous belt or perforated screen and subjected to multiple rows of fine water jets produced to supply pressures around $10-30 \mathrm{MPa}$, which is considerably lower than in many cutting and cleaning applications. Under the influence of the jets, fibres near the surface of the web are pushed down to the lower layers of the web structure and deflected by the conveying belt. The resulting fibre rearrangement and intermingling leads to a sheet structure of non-woven fabric. Typical nozzle diameters are around $100 \mu \mathrm{m}$, which are manufactured to create coherent jets to maximize energy transfer to the fibres. To produce fabric webs with widths up to several metres, strips with thousands of holes are fabricated from high-strength materials to ensure very fine dimensional tolerances giving consistency of energy transfer between adjacent nozzles and avoiding the appearance of unsightly flaws in the non-woven fabrics and the deterioration of the fabric quality with time. Some experimental studies have been carried out to characterize the performance of these nozzles. Ghassemieh et al. $[\mathbf{1 0}, \mathbf{1 1}]$ and Begenir et al. [12] considered a limited range of cylindrical nozzles and combinations of cone and capillary. In a series of numerical studies, Vahedi Tafreshi et al. [13-15] simulated the effects of nozzle geometry on jet flow regime and nozzle cavitation.

The characteristics of the external jet or spray depend on the stability of the flow emerging from the orifice. This stability problem has been extensively researched for cylindrical capillary nozzles. Mansour and Chigier [16] measured flow characteristics and disturbance growth rates of laminar and turbulent jets emerging from cylindrical nozzles with high $L / D$ (36 and 255). This work as well as a recent review of the theory by Lin and Reitz [17] concluded that linear theory provides an adequate description of the mechanisms leading to jet break-up. However, the resulting correlations for jet stability parameters such as break-up length, spray angle, and mean drop size contain empirical factors to account for the initial disturbance levels experienced by the emerging jet. It is currently not possible to evaluate these from first principles for a given nozzle design, so the effects due to upstream flow and nozzle geometry have to be determined experimentally.

In this paper, the results are presented of a wideranging investigation of geometry effects on the flow parameters and jet characteristics of nozzles with diameters between 120-170 $\mu \mathrm{m}$, manufactured for the purpose of creating coherent jets. Cylindrical nozzles with circular and elliptical cross-section were considered. For circular nozzles, the effects of diameter variations and inlet edge roundness were studied, and for elliptical nozzles, variations of the aspect ratio (ratio of major and minor axes) were tested. The findings of a study of interaction effects between adjacent nozzles in multi-hole nozzle configurations are also reported. Flowrate and jet impact force measurements were carried out to determine the discharge coefficient $C_{\mathrm{d}}$ and velocity coefficient $C_{\mathrm{v}}$ of the nozzles for water supply pressures between 3 and $12 \mathrm{MPa}$. Visualizations of the jet flow were carried out in the vicinity of the nozzle exit in order to study jet stability and breakup and to identify the dominant flow regimes. The relationship between nozzle geometry and flow regime is examined.

\section{EXPERIMENTAL METHOD}

\subsection{Flow circuit}

Figure 1(a) shows a diagram of the experimental setup. A three-cylinder reciprocating pump capable of providing pressures up to $25 \mathrm{MPa}$ was used to generate the flow through the nozzle disc holder. Tests were performed with tap water as the fluid at supply pressures ranging from 3 to $12 \mathrm{MPa}$. An accumulator was incorporated in the flow circuit to minimize pressure pulsations due to the pump. A $5 \mu \mathrm{m}$ filter was included to prevent blockage of the nozzle holes. Nozzles were manufactured by punching in stainless steel discs of $0.8 \mathrm{~mm}$ thickness, which were mounted in a nozzle disc holder [Fig. 1(b)] designed to provide a ratio of upstream to nozzle diameter of approximately 200 . The low velocities of the incoming flow $(<1 \mathrm{~cm} / \mathrm{s})$ and the strong contraction means that the kinetic energy of upstream 


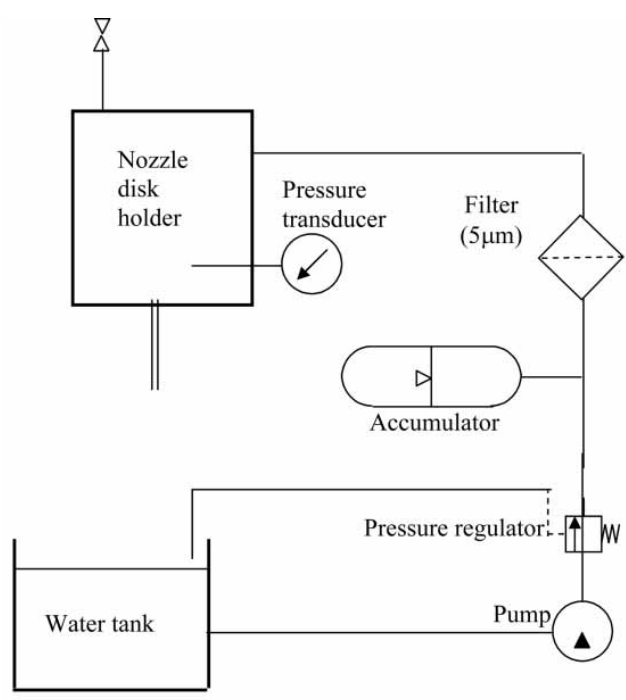

(a) flow circuit

(b) nozzle disk holder

Fig. 1 Schematic of (a) flow circuit and (b) nozzle disk holder

disturbances is very small compared with the kinetic energy of the mean flow in the nozzle.

\subsection{Nozzle geometry}

Circular nozzles with the following geometry variations were studied.

1. Cone-capillary combination nozzles with nominal diameter of $120 \mu \mathrm{m}$, sharp edges, and cone angles $\alpha=10^{\circ}, 15^{\circ}, 25^{\circ}, 35^{\circ}, 45^{\circ}, 60^{\circ}, 75^{\circ}, 90^{\circ}$, and $120^{\circ}$ in configurations cone-up [Fig. 2(a)] and cone-down [Fig. 2(b)]. The nominal length of the capillary section was $180 \mu \mathrm{m}$ for all nozzles, which correspond to a length-to-diameter ratio $L / D=1.5$.

2. Conical nozzles with nominal diameter of $120 \mu \mathrm{m}$, sharp edges, and cone angles $\alpha=10^{\circ}, 15^{\circ}, 25^{\circ}, 35^{\circ}$, $45^{\circ}, 60^{\circ}$, and $75^{\circ}$ in configurations cone-up [Fig. 2(c)] and cone-down [Fig. 2(d)].

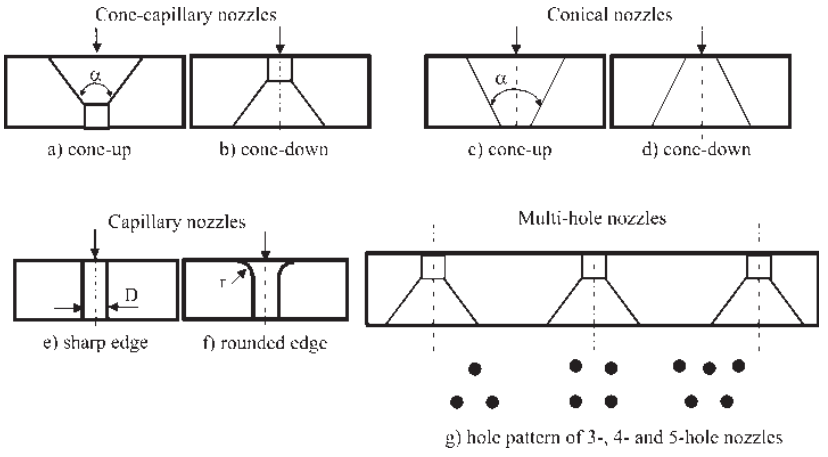

Fig. 2 Sketches of nozzle geometries

3. Capillary nozzles with varying nominal diameters $D=120,150$, and $170 \mu \mathrm{m}$ and sharp edges [Fig. 2(e)].

4. Capillary nozzles with nominal diameter of $120 \mu \mathrm{m}$ and variable edge radius $r=2,5,10,15$, and $25 \mu \mathrm{m}$ [Fig. 2(f)].

5. Three-hole, four-hole, and five-hole conecapillary combination nozzles with nominal diameter of $120 \mu \mathrm{m}$, sharp edges, and cone angles $\alpha=15^{\circ}$ in configurations cone-up and cone-down [Fig. 2(g)].

Elliptical nozzles with the following geometry variations were studied.

1. Capillary nozzles with sharp edges and major and minor axis pairs $(\mathrm{a}, \mathrm{b})=(340 \mu \mathrm{m}, 85 \mu \mathrm{m})$, $(240 \mu \mathrm{m}, 120 \mu \mathrm{m}),(170 \mu \mathrm{m}, 130 \mu \mathrm{m}),(170 \mu \mathrm{m}$, $85 \mu \mathrm{m}),(139 \mu \mathrm{m}, 104 \mu \mathrm{m})$, and (212 $\mu \mathrm{m}, 106 \mu \mathrm{m})$.

The manufacturer Nippon nozzle quoted tolerances of $+2 /-0 \mu \mathrm{m}$. All nozzles were examined by scanning electron microscopy to investigate any manufacturing faults that might adversely affect the flow or diameter tolerances that can affect the measurements (Fig. 3).

\subsection{Flow and force measurements}

The mass flowrate $\dot{m}$ through the nozzles was obtained by measuring the time $\Delta t$ needed to collect a mass of water $\Delta m$ using $\dot{m}=\Delta m / \Delta t$. The water

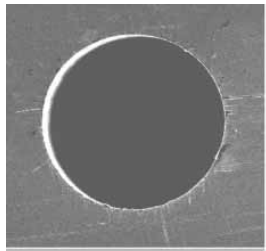

(a) $r=2 \mu \mathrm{m}$

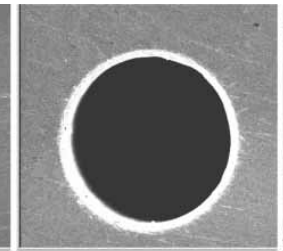

(b) $r=10 \mu \mathrm{m}$

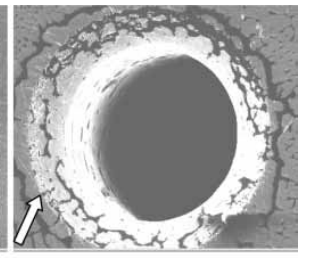

(c) $r=25 \mu \mathrm{m}$
Fig. 3 Scanning electron micrographs of capillary nozzles with different edge roundness 
supply pressure $P$ was measured using a calibrated pressure transducer with an accuracy better than \pm 0.5 per cent of the reading and a resolution of $10 \mathrm{kPa}$. The water was drawn from a large reservoir, the temperature of which underwent slow fluctuations $\pm 2^{\circ} \mathrm{C}$ in response to ambient temperature variations during the test period. The discharge coefficient $C_{\mathrm{d}}$ can now be calculated as follows

$$
C_{\mathrm{d}} \equiv \frac{4 \dot{m}}{\pi D^{2} \sqrt{2 P \rho}}
$$

The mass flowrate measurement can be made very accurate by increasing the liquid collection time. If the density $\rho$ is evaluated at the correct water temperature, the uncertainty in $C_{\mathrm{d}}$ is almost entirely associated with the uncertainty in the nozzle diameter. Expressed as an absolute error, the maximum uncertainty in $C_{\mathrm{d}}$ is estimated to be \pm 0.01 .

The impact force $F$ of the vertical jet on a horizontal target was measured to a resolution of $1 \mathrm{mN}$ using calibrated laboratory scales. The force on the target was recorded throughout by steady-state operation and subsequent removal of the supply pressure. The switch-off transient was found to be very rapid and clearly defined in the force record. Impact force $F$ was obtained from the difference in the force transducer signal just before and just after switch-off, thus eliminating the effect of the weight of the small quantity of water on the target.

The jet impact force is related to the mass flowrate $\dot{m}$ and the jet velocity $V_{j}$ by $F=\dot{m} V_{j}$. Thus, the velocity coefficient $C_{\mathrm{v}}$ can be calculated using equation (2) as

$$
C_{\mathrm{v}} \equiv \frac{V_{j}}{\sqrt{2 P / \rho}}=\frac{F \sqrt{\rho}}{\dot{m} \sqrt{2 P}}
$$

The accuracy of the velocity coefficient is governed largely by the repeatability of the force measurements. A minimum of five force measurements were performed for each nozzle geometry and average values are reported. The maximum uncertainty in the $C_{\mathrm{v}}$ values was estimated to be \pm 0.02 , largely associated with the spread of our force measurements.

Finally, the contraction coefficient of the nozzle is computed from the discharge and velocity coefficients as follows

$$
C_{\mathrm{c}}=C_{\mathrm{d}} / C_{\mathrm{v}}
$$

The maximum uncertainty in computed contraction coefficients is estimated to be \pm 0.025 .

\subsection{Near-nozzle flow visualizations}

High-speed video visualizations were made using a laser-based imaging system consisting of a copper vapour laser generating $2 \mathrm{~mJ}, 30 \mathrm{~ns}$ pulses synchronized with a Kodak Ektapro CCD camera for image acquisition at 9000 frames per second. In this paper, a selection of high-resolution still images in the near-nozzle region is included to illustrate typical external jet structures observed in the high-speed video sequences. These were obtained using a Kodak Megaplus camera with an array of $2000 \times 2000$ pixels using a Nd:Yag laser to deliver $100 \mathrm{~mJ}, 8 \mathrm{~ns}$ pulses to pump a Rhodamine-640 dye cell to provide backlighting of the flowfield. This system in conjunction with a macro lens arrangement enabled us to image $1.1 \times 1.1 \mathrm{~mm}$ square regions.

\section{RESULTS}

\subsection{Cone-capillary nozzles}

Nozzles with cone-capillary design are most commonly used in industrial hydroentanglement practice. Figure 4 shows the discharge coefficients

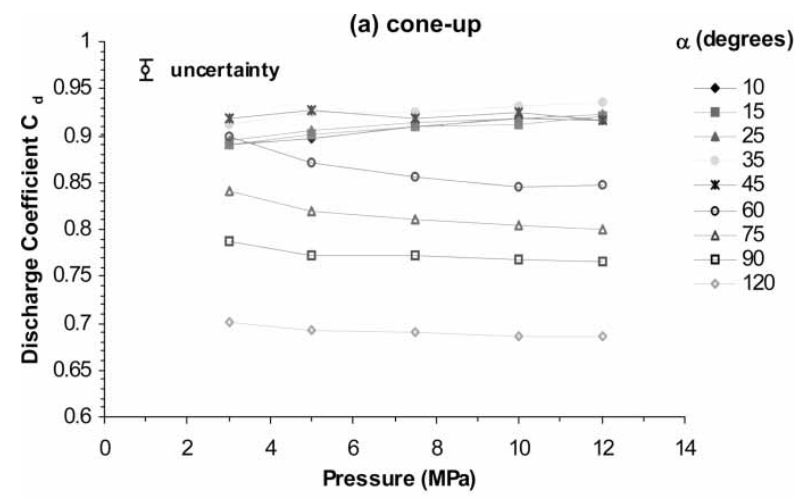

(b) cone-down

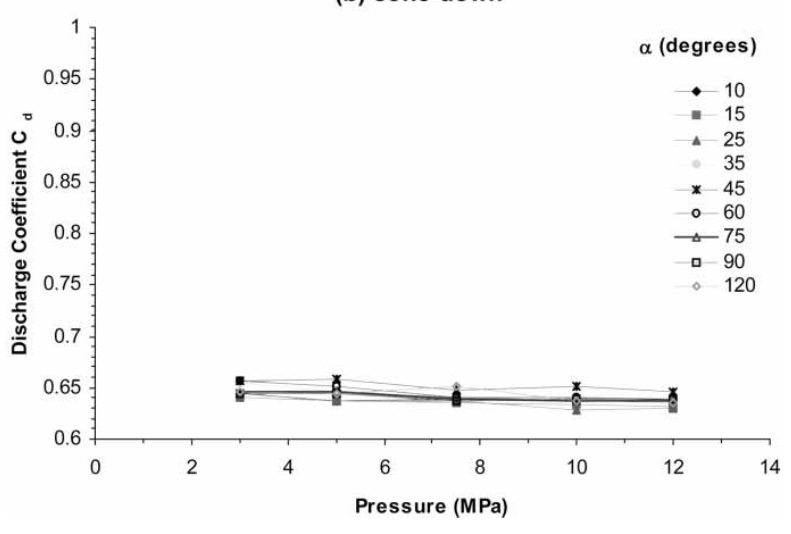

Fig. 4 Discharge coefficient as function of supply pressure for cone-capillary nozzles in configurations: (a) cone-up and (b) cone-down 
for this type of nozzle as function of the cone angle $\alpha$ for cone-up and cone-down configurations. The results for discharge coefficient of the cone-up nozzles [Fig. 4(a)] indicate two distinct behaviours:

(a) Cone angles $\alpha \leq 45^{\circ}$ : high values of discharge coefficient between 0.89 and 0.95 , which is relatively independent of cone angle. For cone angles $35^{\circ}$ and $45^{\circ}$, the value of $C_{\mathrm{d}}$ is substantially independent of supply pressure, whereas at lower cone angles the discharge coefficient shows a slight increase as the supply pressure increases;

(b) Cone angles $\alpha \geq 60^{\circ}$ : reducing values of discharge coefficient, which is strongly dependent on cone angle and which decreases as the supply pressure increases.

The cone-down nozzles [Fig. $4(\mathrm{~b})$ ] yield $C_{\mathrm{d}}$ values that are clustered in a tight band around $0.64-0.65$, indicating that their performance is practically independent of geometry.

Figure 5 shows the velocity coefficients for cone-capillary nozzles in cone-up [Fig. 5(a)] and cone-down configurations. For all geometries, the velocity coefficient rises with supply pressure for all cone angles. The values of $C_{\mathrm{v}}$ vary between 0.9
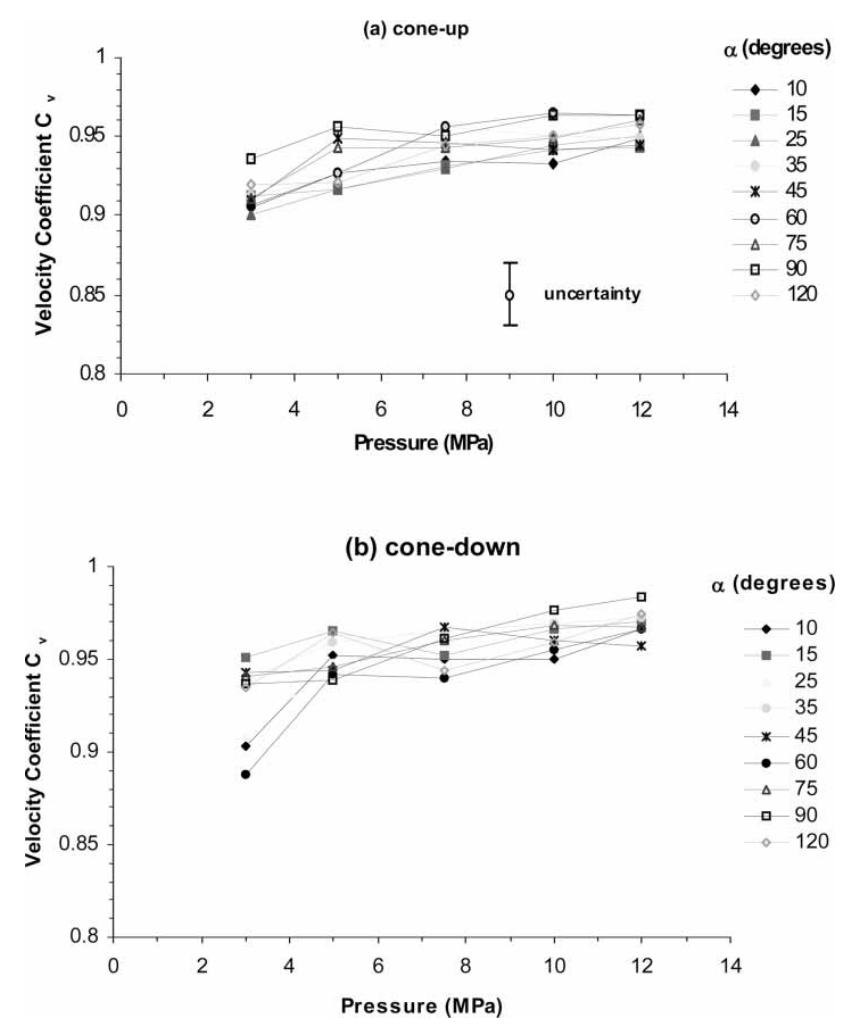

Fig. 5 Velocity coefficient as function of supply pressure for cone-capillary nozzles in configurations: (a) cone-up and (b) cone-down and 0.94 for the cone-up nozzles and between 0.93 and 0.98 for the cone-down nozzles, except for some outlying results at the lowest supply pressure. The difference between the two groups is just larger than the estimated uncertainty of $C_{\mathrm{v}}$. Within each of these two groups of nozzles, the differences in $C_{\mathrm{v}}$ for the cone angles tested are smaller than the uncertainty in the measurement, but within the cone-up group the velocity coefficient appears to be systematically lower by 0.01-0.02 for the group of nozzles with cone angles $\alpha \leq 45^{\circ}$.

\subsection{Conical nozzles}

Figure 6 compares $C_{\mathrm{d}}$ and $C_{\mathrm{v}}$ for conical nozzles and cone-capillary nozzles in the cone-up configuration to examine the effect of the capillary. The results are presented in two sets - cone angles $\alpha \leq 35^{\circ}$ and $45^{\circ} \leq \alpha \leq 75^{\circ}-$ identified as here. $C_{\mathrm{d}}$ and $C_{\mathrm{v}}$ values for conical nozzles with cone angles $\alpha \leq 35^{\circ}$ [Figs 6(a) and (c)] are consistently slightly larger than those of the corresponding cone-capillary nozzles. For cone angles $45^{\circ} \leq \alpha \leq 75^{\circ}$ [Figs $6(\mathrm{~b})$ and (d)], on the other hand, the $C_{\mathrm{d}}$ and $C_{\mathrm{v}}$ values for conical nozzles are very close to those of the cone-capillary nozzles, indicating that the presence of the downstream capillary tube does not appear to affect the performance for this range nozzle geometries.

\subsection{Capillary nozzles}

Next, systematic variations of the edge radius are studied for a series of capillary nozzles with a diameter of $120 \mu \mathrm{m}$. Figure 7 shows the discharge, velocity, and contraction coefficients for these nozzles, which suggests three different behaviours.

1. Radius $r=15,25 \mu \mathrm{m}$, corresponding to $r / D \geq$ 0.125: (a) coefficients are independent of edge radius, (b) high values of $C_{\mathrm{d}}$ between 0.78 and 0.83 decrease with increasing supply pressure, (c) comparatively low values of $C_{\mathrm{v}}$ between 0.88 and 0.96 increasing with increasing supply pressure, and (d) high values of $C_{\mathrm{c}}$ ranging from 0.83 to 0.94 , which decrease strongly with increasing supply pressure.

2. Radius $r=10 \mu \mathrm{m}$, corresponding to $r / D \approx 0.08$ : all coefficients have intermediate values, (a) $C_{\mathrm{d}} \approx 0.74-0.75$ is almost independent of supply pressure, (b) $C_{\mathrm{v}}$ varies between 0.90 and 0.96 increasing with increasing supply pressure, and (c) $C_{\mathrm{c}}$ ranges from 0.75 to 0.85 and decreases strongly with increasing supply pressure.

3. Radius $r=0,2$, and $5 \mu \mathrm{m}$, corresponding to $r / D \leq 0.042$ : (a) coefficients are independent of 

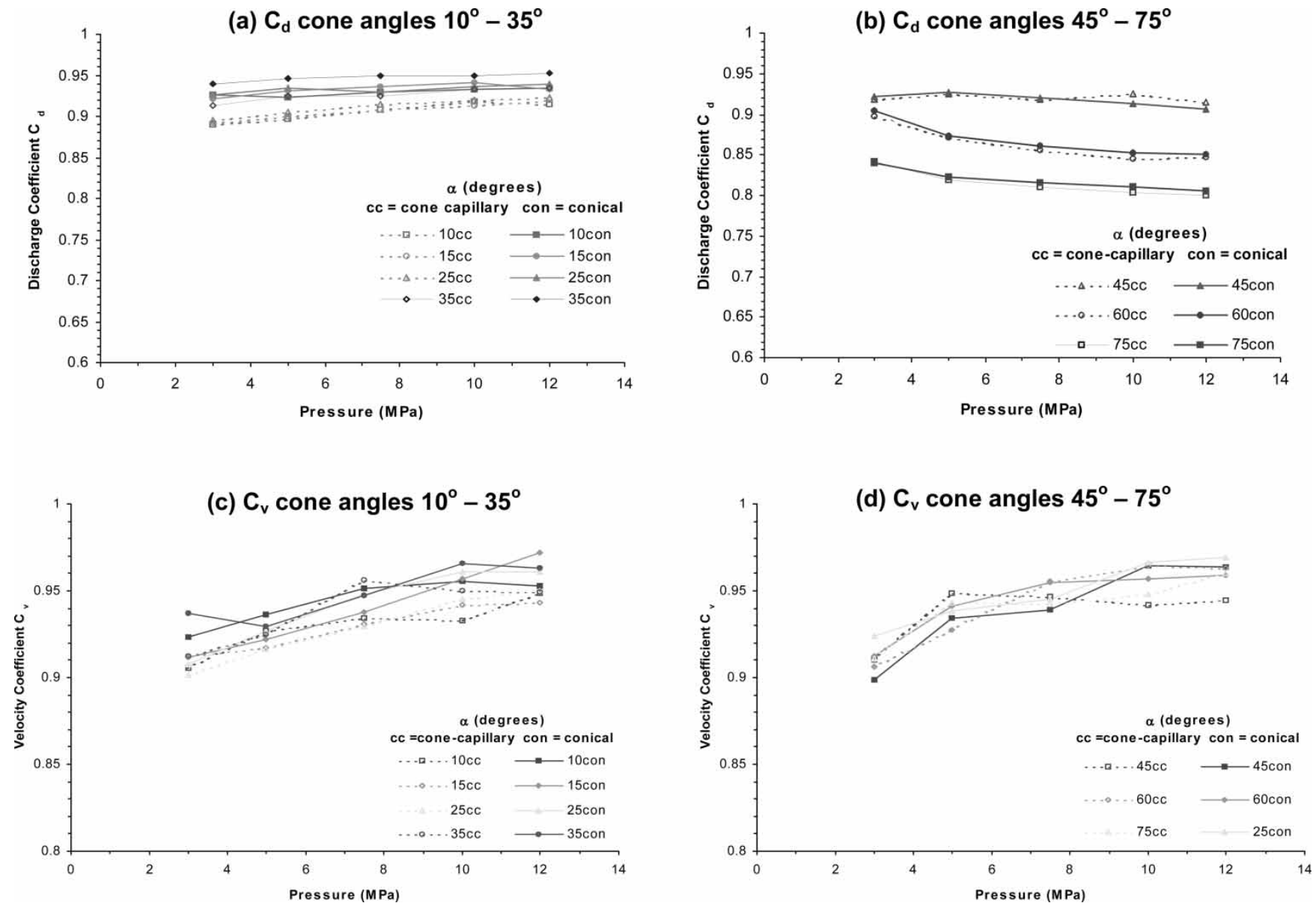

Fig. 6 Comparison of discharge coefficient and velocity coefficient as functions of supply pressure for single-cone and cone-capillary nozzles in cone-up configuration

edge radius, (b) low values of $C_{\mathrm{d}} \approx 0.64-0.65$ decreasing with increasing supply pressure, (c) highest values of $C_{\mathrm{v}}$ varying from 0.93 and 0.98 increasing with increasing supply pressure, and (d) lowest values of $C_{\mathrm{c}}$ ranging from 0.66 to 0.70 , which decrease strongly with increasing supply pressure.

Figure 8 shows discharge, velocity, and contraction coefficient values for straight capillary nozzles with three different diameters as a function of supply pressure. The $C_{\mathrm{d}}$ values [Fig. 8(a)] range between 0.64 and 0.65 . These results and the decreasing trends as a function of pressure closely mirror those for sharp-edged capillary nozzles and conecapillary nozzles in the cone-down configuration. This is further confirmed by the results for velocity and contraction coefficient [Figs 8(b) and (c)]. The geometry changes produce differences that are close to the uncertainty limits of our experiments, which leads us to conclude that the coefficients are substantially independent of geometry for the range of diameters tested.

\subsection{Elliptical nozzles}

Table 1 gives a summary of the geometrical parameters of the capillary nozzles with elliptical cross-section that were studied.

The first two columns give the lengths of major axis $a$ and minor axis $b$ and the third column contains the aspect ratio $a / b$. The fourth and fifth columns contains the hydraulic diameter $D_{\mathrm{h}}$ and the equivalent diameter $D_{\mathrm{e}}$, which are defined as follows

$$
\begin{aligned}
D_{\mathrm{h}} & =\frac{4 A_{\mathrm{N}}}{\wp} \\
& \approx \sqrt{a b} \frac{1}{\sqrt{(1 / 2)(a / b)\left[1+(a / b)^{2}\right]}}
\end{aligned}
$$

to accuracy better than 10 per cent

$$
D_{\mathrm{e}}=\sqrt{\frac{4 A_{\mathrm{N}}}{\pi}}=\sqrt{a b}
$$


(a) discharge coefficient

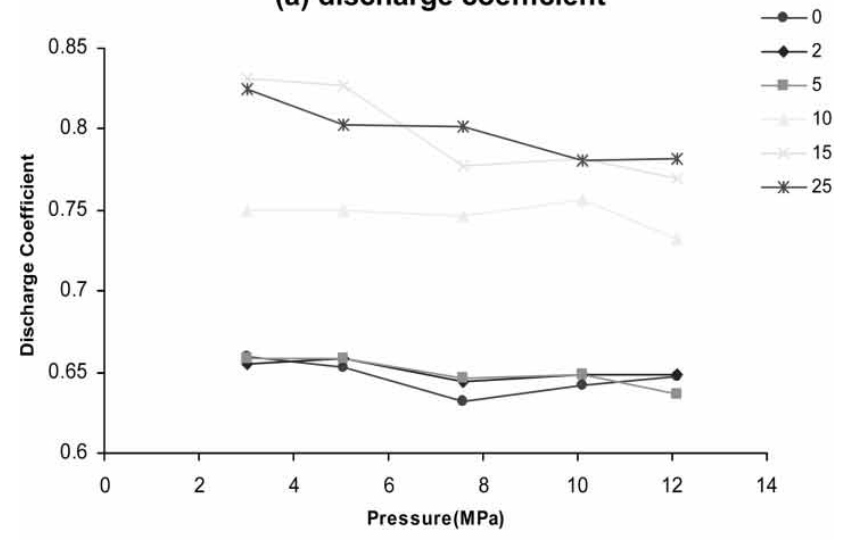

(b) velocity coefficient

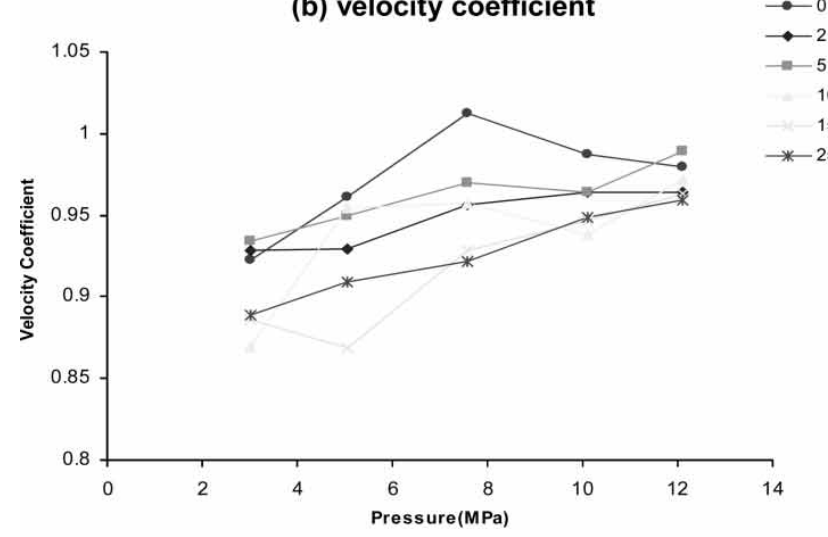

(c) contraction coefficient

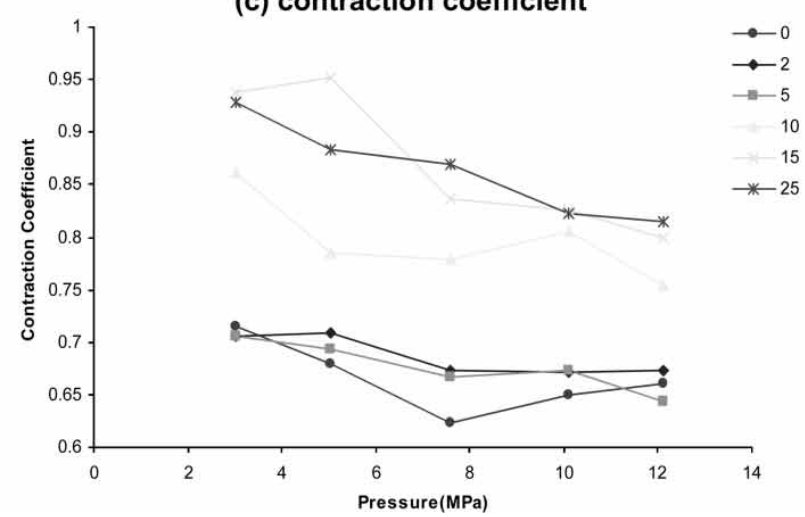

Fig. 7 Effect of edge radius on flow characteristics of circular nozzles (a) discharge coefficient, (b) velocity coefficient, and (c) contraction coefficient

The table shows that three different values of aspect axis ratio $a / b$ were selected: $1.33,2$, and 4. These were tested in combination with three different values of equivalent diameter: 120, 150, and $170 \mu \mathrm{m}$, respectively, corresponding to the diameters of the capillary nozzles tested earlier. The hydraulic diameters are somewhat different, particularly for the highest aspect ratio.

Figure 9 gives the discharge, velocity, and contraction coefficients for the six elliptical nozzles. (a) discharge coefficient

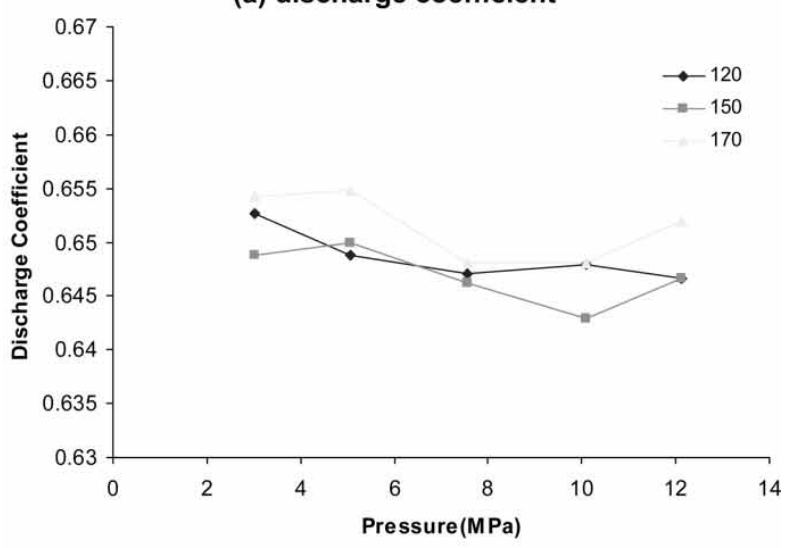

(b) velocity coefficient

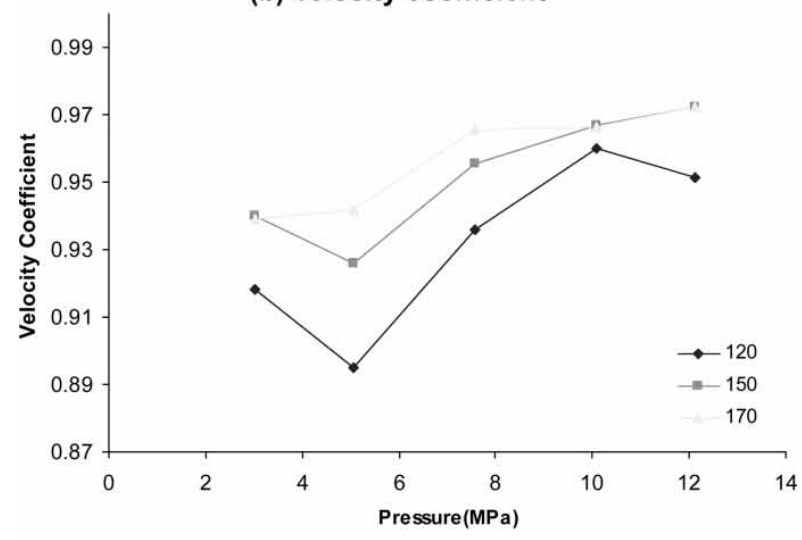

(c) contraction coefficient

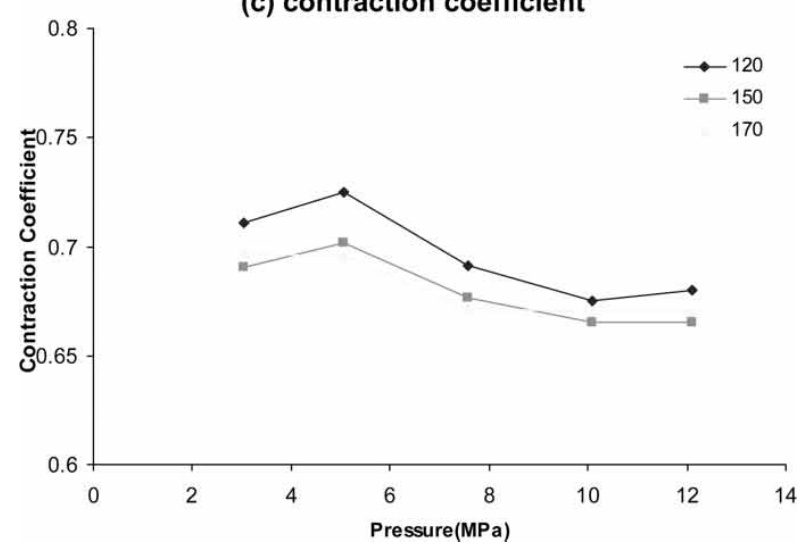

Fig. 8 Effect of diameter on flow characteristics of capillary nozzles (a) discharge coefficient, (b) velocity coefficient, and (c) contraction coefficient

Table 1 Geometrical parameters of elliptical nozzles

\begin{tabular}{lclll}
\hline$a(\mu \mathrm{m})$ & $b(\mu \mathrm{m})$ & $a / b$ & $D_{\mathrm{h}}(\mu \mathrm{m})$ & $D_{\mathrm{e}}(\mu \mathrm{m})$ \\
\hline 170 & 130 & 1.31 & 146.0 & 148.7 \\
139 & 104 & 1.34 & 117.7 & 120.2 \\
240 & 120 & 2.00 & 151.8 & 169.7 \\
170 & 85 & 2.00 & 107.5 & 120.2 \\
212 & 106 & 2.00 & 134.1 & 149.9 \\
340 & 85 & 4.00 & 116.6 & 170 \\
\hline
\end{tabular}




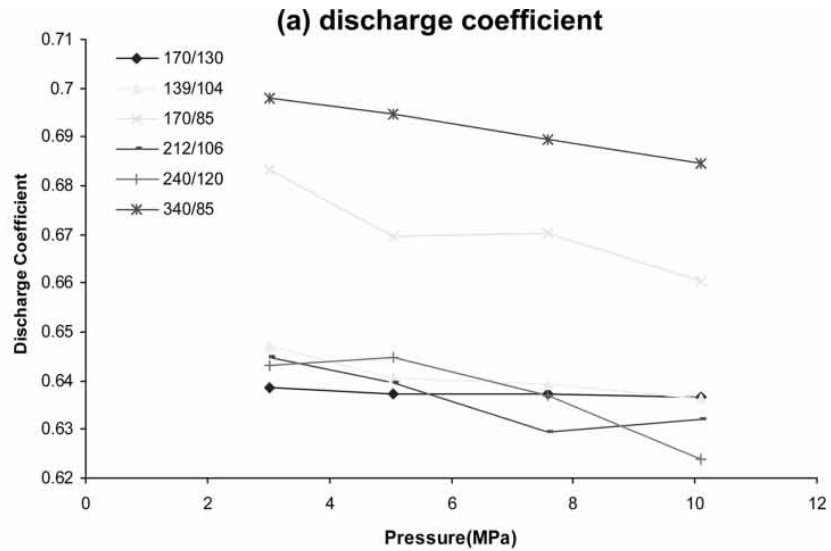

(b) velocity coefficient

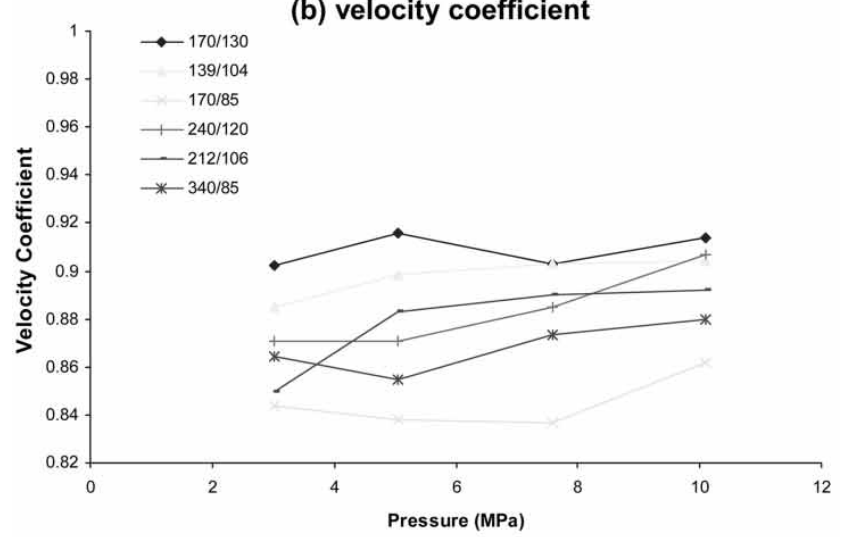

(c) contraction coefficient

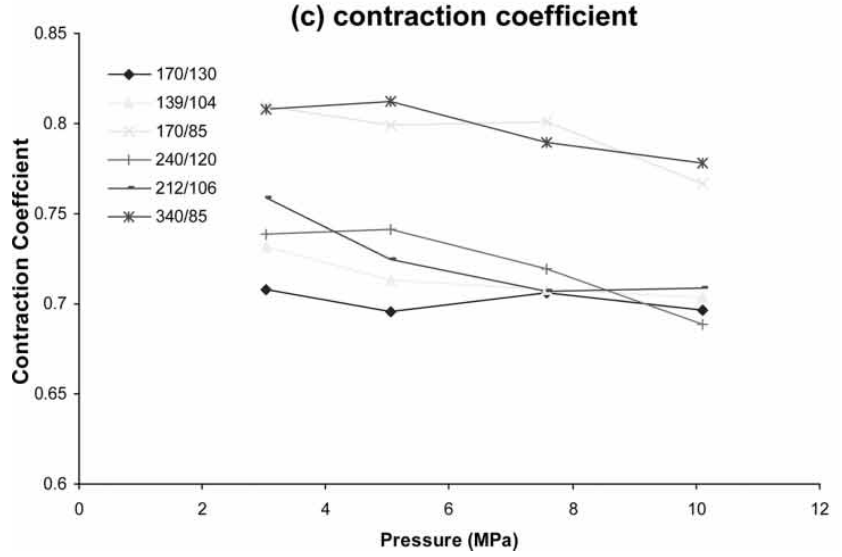

Fig. 9 Effect of major/minor axis ratio on flow characteristics of elliptical nozzles (a) discharge coefficient, (b) velocity coefficient, and (c) contraction coefficient

The results show that the characteristics of four nozzles $-(a, b)=(170,130),(139,104)$, $(240,120)$, and $(212,106)$ - are very similar to those of capillary nozzles with circular cross-section. Two others, namely $(170,85)$ and $(340,85)$, have higher discharge coefficients. The contraction coefficient of these nozzles is considerably higher, but this is offset by a lower velocity coefficient.

\subsection{Multi-hole nozzles}

The discharge coefficients of single hole and multihole cone-capillary nozzles are compared in Fig. 10. The dependence of $C_{\mathrm{d}}$ on pressure for multi-hole nozzles closely follows the trends of the corresponding single hole nozzle: increasing with increasing pressure for cone-up and decreasing for conedown. However, $C_{\mathrm{d}}$ for multi-hole nozzles is on average slightly higher, suggesting a small interaction effect. Inspection of the nozzle bores using SEM did not reveal measurable diameter variations that might be responsible. The most likely cause is a distortion of the liquid flow patterns just upstream of the nozzle or changes in air flow patterns in the exit region leading to a small increase in the contraction coefficient.

\subsection{Flow visualizations}

Figure 11 shows two sequences of high-speed flow visualizations for the nozzles with cone angles of $25^{\circ}$ and $60^{\circ}$ for supply pressures ranging from 0.6 to $10 \mathrm{MPa}$. The visualizations relating to the nozzle with cone angle of $25^{\circ}$ [Fig. 11(a)] highlight a flow instability that leads to a fuzzy jet appearance and spray formation. At low pressures, the jet is transparent and the surface is undisturbed. As the pressure is increased to $1.2 \mathrm{MPa}$ occasional large amplitude disturbances start to appear on the jet surface at random intervals. Upon further increase of the pressure, these disturbances are found to occur more frequently. At pressures above $3 \mathrm{MPa}$, disturbances completely cover the jet surface and further increase of the pressure causes an increase of the magnitude of the largest disturbances. The

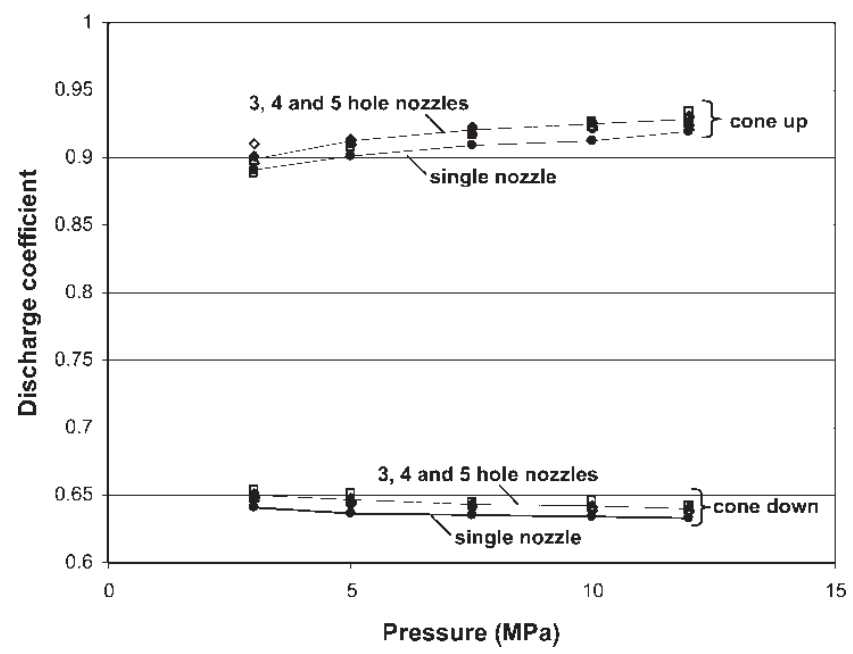

Fig. 10 Effect of number of holes on discharge coefficients of cone-capillary nozzles in multi-hole configurations 


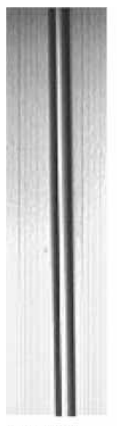

$0.6 \mathrm{MPa}$

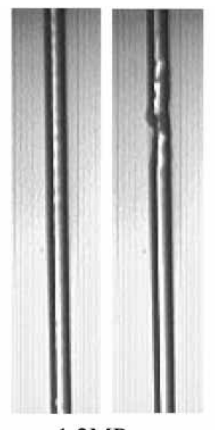

1.2 $\mathrm{MPa}$

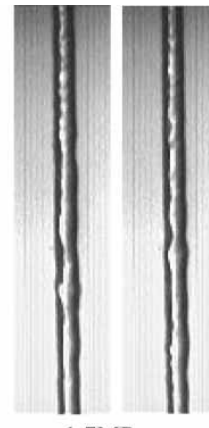

$1.7 \mathrm{MPa}$

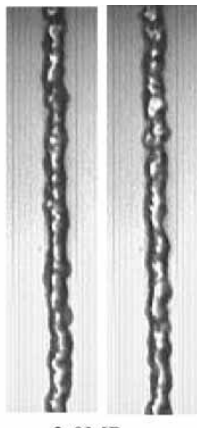

3.0MPa

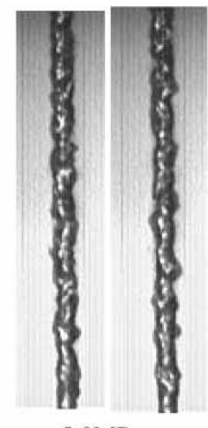

5.0MPa

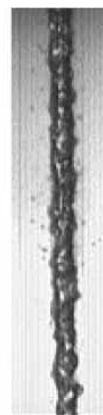

7.5 $\mathrm{MPa}$

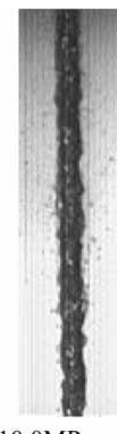

10.0MPa

(a) Cone-capillary cone-up $25^{\circ}$
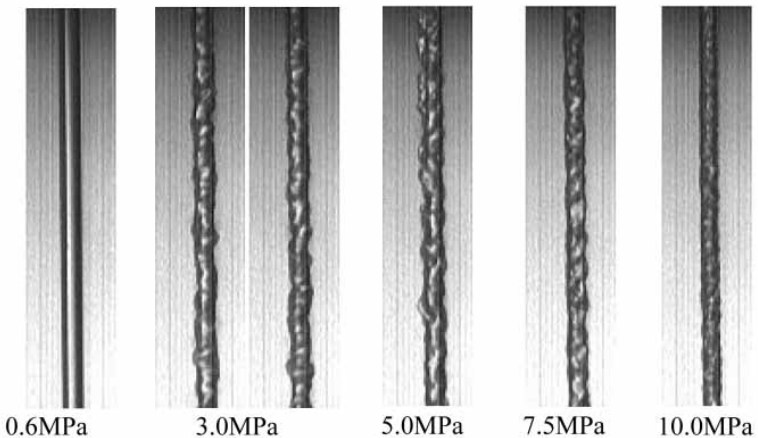

(b) Cone-capillary cone-up $60^{\circ}$

Fig. 11 High-speed near-nozzle flow visualizations at $P=0.6-10 \mathrm{MPa}$ for cone-capillary nozzles: (a) $\alpha=25^{\circ}$ and (b) $\alpha=60^{\circ}$ in cone-up configuration

behaviour of these jets is typical of the near-nozzle flow characteristics for nozzles with fully attached capillary flows, such as cone-up nozzles at low cone angles $10^{\circ} \leq \alpha \leq 35^{\circ}$ as well as capillary nozzles with rounded inlet edge. At pressures above $5 \mathrm{MPa}$, these jets are found to produce substantial amounts of fine droplet mist. This ties in with the small droplets that are clearly visible in the visualizations at 7.5 and $10 \mathrm{MPa}$ alongside the jet. This droplet stripping from the jet surface causes a loss of fluid mass, but the main jet remains intact over the entire distance between nozzle and impact surface (approximately $5 \mathrm{~cm}$ ). The visualizations for the cone angle of $60^{\circ}$ [Fig. 11(b)] show that the lowpressure behaviour is similar to the case of $\alpha=25^{\circ}$. The disturbance frequency increases with pressure up to $3 \mathrm{MPa}$, but at higher pressure the disturbance amplitude and frequency gradually decrease and the width of the jet also decreases. The behaviour of these jets is typical of the near-nozzle flow characteristics for cone-up nozzles at intermediate cone angles, $45^{\circ} \leq \alpha \leq 60^{\circ}$.

Figures 12(a) and (b) show images of near-nozzle flows produced by cone-down nozzles with $\alpha=25^{\circ}$ and $60^{\circ}$. All of the jets produced by nozzles in the cone-down configuration have a clear, transparent appearance, the jets are highly coherent. Neither the jet width, nor its appearance changes throughout the range of pressures achievable with our equipment (0.6-12 MPa). The images are virtually identical and typical of all cone-capillary nozzles, as well as those of conical nozzles in the conedown configuration [Figs 12(c) and (d)] and also sharp-edged capillary nozzles. Visualizations of conical nozzles show that the jets are also clear and transparent in the cone-up configurations. For cone-up nozzles, the disturbed appearance and droplet mist production of cone-capillary nozzles are largely absent.
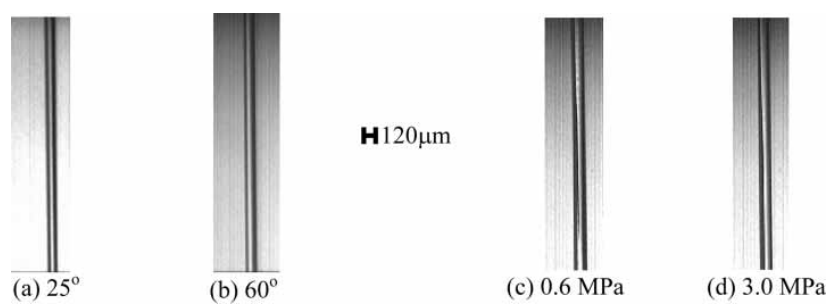

Fig. 12 High-speed near-nozzle flow visualizations for nozzles in cone-down configuration: conecapillary nozzles at $P=10 \mathrm{MPa}$ : (a) $\alpha=25^{\circ}$ and (b) $\alpha=60^{\circ}$, Conical nozzle $\alpha=60^{\circ}$, (c) $P=0.6$ and (d) $3 \mathrm{MPa}$ 


\section{DISCUSSION}

\subsection{Capillary nozzles and cone-capillary nozzles in cone-down configuration}

Capillary nozzles have been most widely researched to date. Table 2 compares our discharge coefficient measurements with a selection of published data.

Early observations by Bergwerk [1] of transparent models of fuel injector nozzles - subsequently confirmed in many other studies, see references [18] and $[19]$ - revealed a strong correlation between the internal flow regime and external jet flow characteristics. A supercavitating internal flow state, now known as hydraulic flip, was found to occur at cone angles where the fluid separates without much disturbance from the walls of the capillary forming a coherent jet with a high break-up length. Where the internal flow remains attached, the external jet flow was found to have a 'ruffled' appearance and atomise more readily. Bergwerk [1] found that the onset of cavitation for a sharp edged orifice is around 0.3 MPa. Results from Fox and Stark [20] indicate hydraulic flip at $0.35 \mathrm{MPa}$ for a capillary tube nozzle with $L / D=3$. The minimum pressure that is achievable in our test rig is $0.6 \mathrm{MPa}$ and the transparent appearance of the jets produced by capillary nozzles and cone-capillary nozzles in the conedown configuration (Fig. 12) confirms that all have undergone hydraulic flip.

Table 2 shows that our $C_{\mathrm{d}}$ values for sharp-edged capillary nozzles and cone-capillary nozzles in the cone-down configuration compare favourably with those of others. Differences between our datasets were found to be smaller than 0.015 , which is within the 'headline' uncertainty estimate of \pm 0.01 for the $C_{\mathrm{d}}$ values. Thus, our test procedure could not identify a statistically significant effect of geometry on $C_{\mathrm{d}}$. Similar remarks apply to the velocity coefficient $C_{\mathrm{v}}$ data in this category of nozzles.

Close inspection of the data shows a small decrease of $C_{\mathrm{d}}$ around 0.01 as the supply pressure increases. It should be noted that the main contribution to the uncertainty in the discharge coefficient is caused by the uncertainty in the orifice diameter. This introduces an identical systematic bias to all measurements made with a given nozzle. While the value of $C_{\mathrm{d}}$ for that particular nozzle will be uncertain to within \pm 0.01 , the uncertainty excluding bias due to inaccuracy in the diameter measurement is estimated to be at most \pm 0.003 . Thus, variations of $C_{\mathrm{d}}$ around 0.01 for that nozzle used with different supply pressures are significant. For submerged sharp-edged orifices and increases from $\mathrm{Re}=6000$ to 12 000, the Reynolds number correction of Fried and Idelchik [21] predicts a decrease of $C_{\mathrm{d}}$ of 0.02 , which is somewhat larger than our measured value. Some discrepancies are to be expected due to the absence of surface tension effects and differences in viscous effects in the flow through a submerged orifice. Ohrn et al. [7] did not report an effect of Reynolds number on the discharge coefficient of sharp-edged orifices. However, a small decrease of $C_{\mathrm{d}}$ was found with increasing $R e$ for short capillary nozzles with rounded inlet edges $(r / D=0.05$ and 0.16 ) and a slight increase for larger $r / D$. This would suggest that manufacturing tolerances have played a part.

Table 2 Comparison of $C_{\mathrm{d}}$ values for capillary and cone-down nozzles

\begin{tabular}{|c|c|c|c|c|c|}
\hline \multicolumn{3}{|c|}{ Geometry } & \multirow[b]{2}{*}{$C_{\mathrm{d}}$} & \multirow[b]{2}{*}{$R e_{\mathrm{D}}$} & \multirow[b]{2}{*}{ Source } \\
\hline$L / D$ & $r / D$ & $D(\mu \mathrm{m})$ & & & \\
\hline $2-5$ & $\begin{array}{l}\text { Sharp } \\
0.05 \\
0.15 \\
0.25 \\
0.50\end{array}$ & 254 & $\begin{array}{c}0.63 \pm 0.014 \\
0.67-0.72 \\
0.70-0.87 \\
0.85-0.87 \\
0.86-0.97\end{array}$ & $10000-30000$ & Ohrn et al. [7] \\
\hline $1.5-50$ & Sharp & 300 & $0.59-0.69$ & $27000-54000$ & Karasawa et al. [8] \\
\hline 1 & Rounded & 300 & $0.96-0.98$ & & \\
\hline $\begin{array}{l}2 \\
5\end{array}$ & (large $r / D$ ) & & $\begin{array}{l}0.98 \\
0.95-0.97\end{array}$ & & \\
\hline 10 & & & $0.86-0.87$ & & \\
\hline 20 & & & $0.80-0.81$ & & \\
\hline 50 & & & $0.67-0.70$ & & \\
\hline 4 & $60^{\circ}$ chamfer & 300 & 0.81 & & \\
\hline 7.7 & Sharp & 128 & $0.62-0.65$ & $6000-29000$ & Begenir et al. [12] \\
\hline 1 & Cone-down & 128 & $0.62-0.65$ & & \\
\hline $4.7-6.7$ & Sharp & $120-170$ & $0.64-0.66$ & $9000-18000$ & Present data \\
\hline \multirow[t]{3}{*}{6.7} & $\leq 0.04$ & 120 & $0.63-0.66$ & & \\
\hline & 0.08 & & $0.72-0.76$ & & \\
\hline & $\geq 0.16$ & & $0.78-0.83$ & & \\
\hline 1.5 & Cone-down & 120 & $0.63-0.66$ & & \\
\hline
\end{tabular}




\subsection{Effect of edge roundness in capillary nozzles}

The flow characteristics of capillary nozzles are also determined by the presence or absence of flow separation at the inlet edge of the capillary. Hydraulic flip will occur if the edge is sharp or the ratio $r / D$ is sufficiently small, creating a narrow jet which is kept away from the capillary walls by means of a recirculating air flow acting as hydrodynamic lubrication. The values of $C_{\mathrm{d}}, C_{\mathrm{v}}$, and $C_{\mathrm{c}}$ for such nozzles are very close to those of cone-capillary nozzles in the cone-down configuration, confirming once more that the geometry downstream from the separation edge does not have a major influence on the discharge characteristics. When $r / D$ is large, on the other hand, the flow is guided around the inlet corner and will remain attached to capillary walls. This creates a wider jet and increased wall friction and, hence, strongly increased $C_{\mathrm{d}}$ and $C_{\mathrm{c}}$ and slightly reduced $C_{\mathrm{v}}$. The present results indicate that the switch from separated to attached flow takes place around $r / D=0.07-0.1$, which is close to published values for submerged nozzles.

Table 2 confirms that the increase of the discharge coefficient with the edge roundness corresponds to the trends observed by Ohrn et al. [7] and others. Experiments by Chaves et al. [19] and simulations by Schmidt et al. [22] show that this increase is a result of shortening of the cavitation and separation region for rounded nozzles. Figure 13 compares our experimental results with Schmidt's simulations demonstrating that the model fails to capture the behaviour correctly for $0<r / D<0.05$.

\subsection{Effect of diameter in capillary nozzles}

Figure 8 shows that the differences in the measured values of $C_{\mathrm{d}}, C_{\mathrm{v}}$, and $C_{\mathrm{c}}$ in the tests with different diameters for nominally sharp capillaries were smaller than the uncertainty of the tests. It should be noted that the length of the nozzles was kept constant at $800 \mu \mathrm{m}$, so the $L / D$ ratio reduces from 6.7

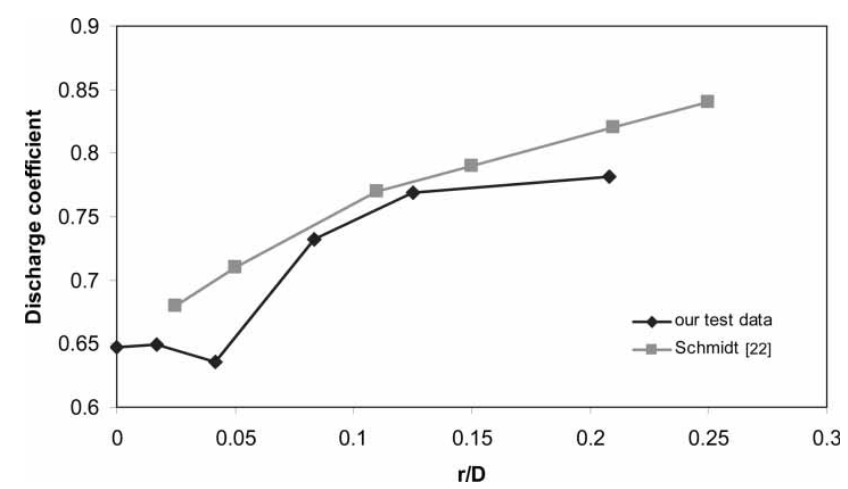

Fig. 13 The effect of edge roundness on the discharge coefficient of capillary nozzles to 4.7 as the diameter increases from 120 to $170 \mu \mathrm{m}$. This is unlikely to have affected the trends given the similarity of the characteristics of our capillary and cone-down cone-capillary nozzles, which have capillary $L / D$ ratios of 6.7 and 1.5 , respectively.

\subsection{Conical nozzles and cone-capillary nozzles in cone-up configuration}

Given the frequent assertions of the importance of inlet conditions by past authors (see e.g. Wu et al. [23]), it is not surprising that variations of the cone angle yield a wide range of $C_{\mathrm{d}}$ values for nozzles in the cone-up configuration. Table 3 compares our results for nozzles with conical entry with a selection of published data.

The wide variety of reported $C_{\mathrm{d}}$ values confirms a strong dependence on geometry, which is further illustrated in Figs 4 to 6 . In conical nozzles, the flow always separates cleanly from the edge at the smallest cross-section and narrows further as it leaves the nozzle. In cone-capillary nozzles, this behaviour is reproduced if the cone angle is sufficiently large. The resulting jets are narrow enough to be shielded from the capillary wall by an air gap, which is the hallmark of hydraulic flip. The combination of a narrow jet and low friction is responsible for the low discharge coefficients and somewhat higher velocity coefficients in these cases. The flow geometry will be more or less identical for conical and cone-capillary nozzles with high cone angle, which explains why the behaviour of all coefficients is almost identical for these two categories of nozzles [Figs 6(b) and (d)]. At low values of $\alpha$, the flow fills the entire capillary section resulting in a high $C_{\mathrm{d}}$ regime involving higher contraction coefficients, but slightly reduced velocity coefficient [Figs 6(a) and (c)].

It is interesting to compare the results for conecapillary nozzles in cone-up configuration at low cone angles with those for capillary nozzles at high $r / D$. In single phase flows we might expect attached flow in both cases. The $C_{\mathrm{d}}$ values for 'low $\alpha$ ' conecapillary nozzles in cone-up configurations are considerably higher than those of 'high $r / D$ ' capillary nozzles. At first glance this might be attributed to increased friction due to the higher $L / D$ of the capillary nozzles (6.7 against 1.5). However, in fully attached flows we would expect to see a corresponding difference between the values of $C_{\mathrm{v}}$. Inspection of Figs 5(a) and 7(b) shows that this is not the case. Furthermore, Figs 4(a) and 7(a) highlights that the trends of $C_{\mathrm{d}}$ with changing pressure are opposite. In fact, the behaviour of 'high $r / D$ ' capillary nozzles is closer to a cone-up cone-capillary nozzle with $\alpha=75^{\circ}$. Such a nozzle has characteristics that are intermediate between fully attached and fully separated flows, indicating partial hydraulic flip. 
Table 3 Comparison of $C_{\mathrm{d}}$ values for nozzles with conical entry

\begin{tabular}{|c|c|c|c|c|c|c|}
\hline \multicolumn{4}{|c|}{ Geometry } & \multirow[b]{2}{*}{$C_{\mathrm{d}}$} & \multirow[b]{2}{*}{$R e_{\mathrm{D}}$} & \multirow[b]{2}{*}{ Source } \\
\hline$\alpha\left(^{\circ}\right)$ & $L / D$ & $L_{\mathrm{c}} / D$ & $D(\mu \mathrm{m})$ & & & \\
\hline \multirow[t]{4}{*}{90} & 2.9 & 0.9 & a & 0.83 & 6500 & Hall [24] \\
\hline & 0.5 & $3^{\mathrm{b}}$ & 340 & $0.90-0.79$ & $26500-45600$ & Reitz and Bracco [25] \\
\hline & 0.5 & $3^{\mathrm{b}}$ & 340 & 0.81 & 40800 & Reitz and Bracco [2] \\
\hline & 1.5 & 5.2 & 120 & $0.78-0.76$ & $9000-18000$ & Present data \\
\hline \multirow[t]{3}{*}{60} & 4.0 & $1^{\mathrm{b}}$ & 300 & 0.81 & c & Karasawa et al. $[\mathbf{8}]$ \\
\hline & 1.5 & 5.2 & 120 & $0.78-0.76$ & $9000-18000$ & Present data \\
\hline & 0.0 & 6.7 & 120 & $0.90-0.85$ & $9000-19000$ & \\
\hline
\end{tabular}

${ }^{\mathrm{a} D i a m e t e r}$ not given.

${ }^{\mathrm{b}} L_{\mathrm{c}} / D$ estimated from diagrams in data source.

${ }^{\mathrm{c} C o n d i t i o n s}$ not given; range of test conditions $26900 \leq R e_{\mathrm{D}} \leq 89500$.

The SEM image in Fig. 2(c) suggests that the rounded edge shape may be slightly discontinuous (see arrow). Such a discontinuity, surface roughness, and streamline curvature in the rounded edge could be jointly responsible for disturbances in the boundary layer or cavitation in a manner that is fundamentally different. Further research is necessary to explore these subtle geometry effects in more detail.

Finally, it is noted that discharge coefficients have been extensively reported in past work. However, to the knowledge of the present authors this is the first set of data that also includes the velocity coefficient. Combining $C_{\mathrm{d}}$ and $C_{\mathrm{v}}$ allows us to evaluate contraction coefficient $C_{\mathrm{c}}$ using equation (3). Figures 14(a) and (b) show the computed values of $C_{\mathrm{c}}$ as a function of cone angle for cone-capillary and conical nozzles, respectively. The diagram also indicates two further lines: (i) $C_{\mathrm{c}}=1$ which represents the upper limit of physically possible values and (ii) potential flow, based on two-dimensional (planar) potential flow theory [26]. The latter theory does not strictly apply to our (axisymmetric) circular nozzles, but has been found in the past to give good estimates of discharge coefficients in this case.

The diagram shows that the contraction coefficient is very close to unity for cone angles $\leq 45^{\circ}$. For some cases, the contraction coefficient is slightly higher than 1, but the deviation is less than our uncertainty estimate of \pm 0.025 for $C_{\mathrm{c}}$. At larger cone angles, the contraction coefficient decreases at a rate that is close to the trend predicted by potential flow, but at somewhat higher values. As regards the variations of the coefficients as functions of the supply pressure, it is interesting to note that our measurements of $C_{\mathrm{d}}$ and $C_{\mathrm{v}}$ reveal that the fluid mechanics is more complex than implied by discharge coefficient measurements only. Thinning of the nozzle boundary layers with increasing Reynolds number causes a reduction in the frictional losses and hence an increase in $C_{\mathrm{v}}$ for all nozzle geometries. For capillary nozzles with sharp inlets or conical nozzles with higher cone angles, this increase is offset by more purely inertial jet formation. This gives rise to a stronger reduction in the contraction coefficient $C_{\mathrm{c}}$ and an overall decrease in $C_{\mathrm{d}}$ for these geometries.

\subsection{Elliptical nozzles}

The discharge coefficient of most elliptical nozzles is similar to those of circular nozzles with the same

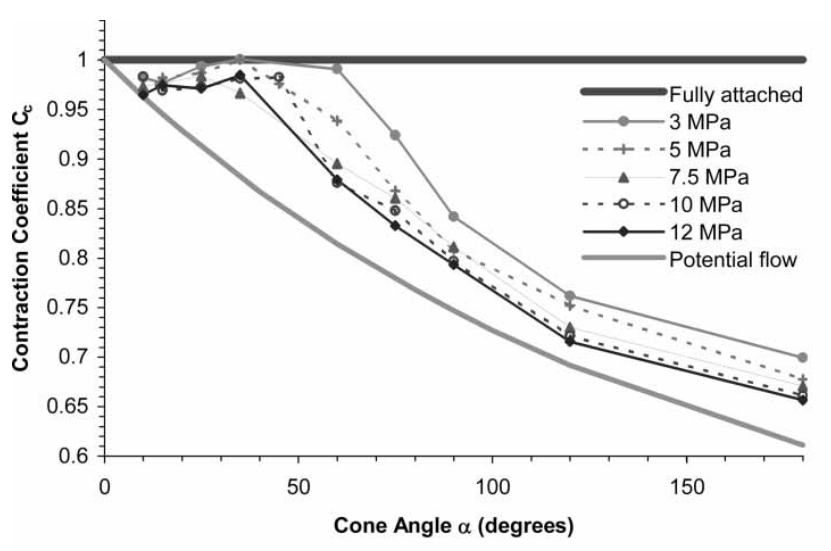

(a) Cone-capillary nozzles

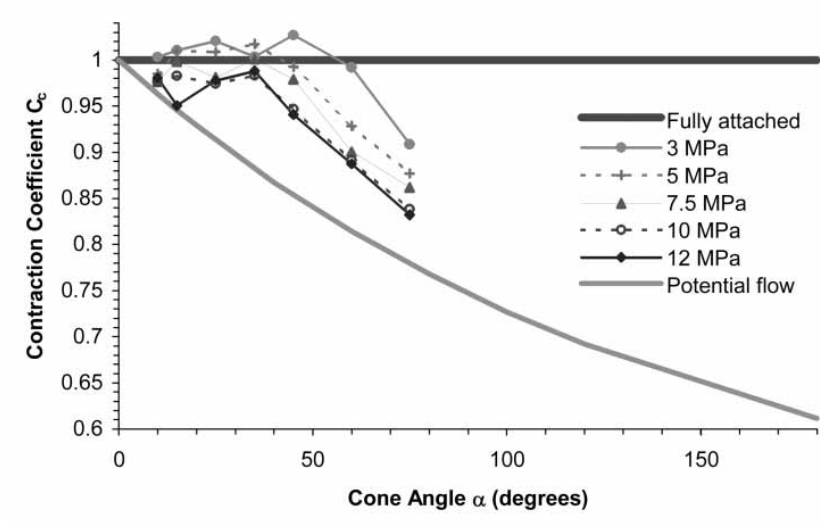

(b) Conical nozzles

Fig. 14 Contraction coefficient as function of cone angle for cone-capillary and conical nozzles 
equivalent diameter. Only the elliptical nozzles with minor axis of $85 \mu \mathrm{m}$ showed higher discharge coefficient. SEM images of these nozzles clarified the reason behind these results. Comparison of the shape of the nozzles with the minor axis of $85 \mu \mathrm{m}$ with a true ellipse reveals that the surface area of these nozzles is somewhat larger than the ellipse with equivalent minor and major axis [Figs 15(a) and (b)]. Thus, the higher discharge coefficient for these nozzles is clearly a result of manufacturing errors.

Despite the similar trend of velocity and discharge coefficient of the elliptical nozzle to the equivalent circular nozzles, flow observations show different jet flow behaviour with periodic switching of flow between the minor and major axes. The effect is strongest in elliptical nozzles with higher aspect ratio. This can be explained in terms of the action of surface tension, which tries to force the emerging stream of fluid to adopt a cylindrical shape. Starting from an elliptical cross-section, the fluid first contracts to a circle, but subsequently overshoots and

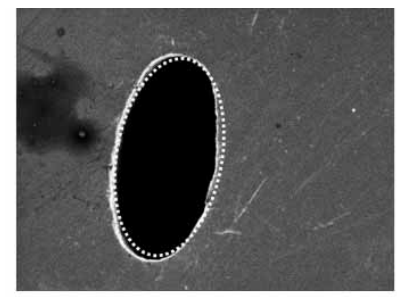

(a)

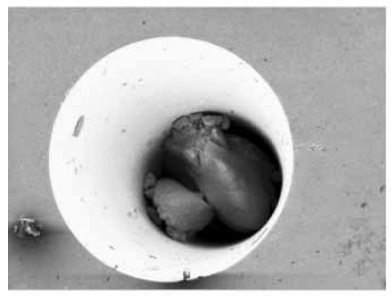

(c)

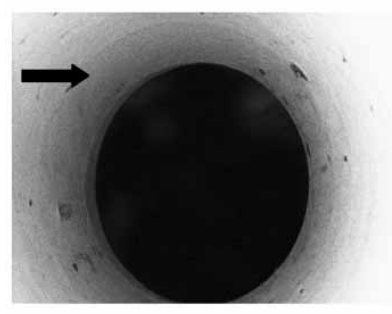

(e)

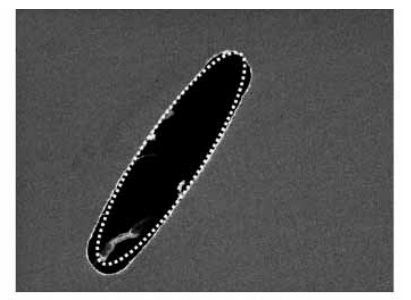

(b)

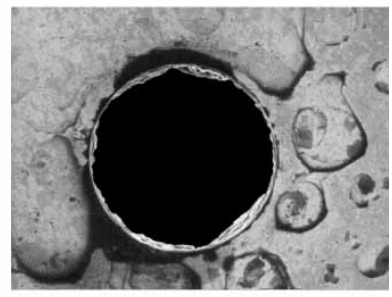

(d)

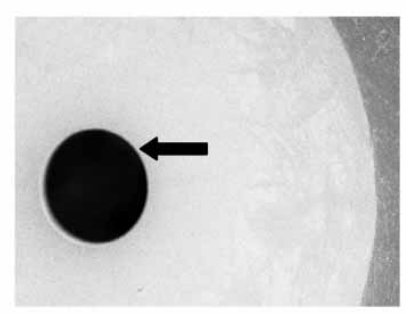

(f)
Fig. 15 SEM images of nozzles: (a) and (b) elliptical nozzle with rough edges, (c) fully blocked nozzle, (d) partially scaled nozzle, (e) rounded cone-capillary junction for $15^{\circ}$ cone angle, and (f) sharp cone-capillary junction for $60^{\circ}$ cone angle forms an ellipse with the direction of major and minor axes switched. The wavelength and damping of this jet shape oscillation depend on liquid viscosity, jet speed, as well as surface tension.

\subsection{Other factors affecting nozzle performance}

Several other factors were found to affect the performance of the nozzles studied in this work.

1. Blockage. Since the nozzles are very small, they readily suffer full or partial blockage. This causes a dramatic reduction of the coherence of the jet and triggers sudden atomization. Figure 15(c) shows an SEM image of a fully blocked nozzle which results in a complete change of flow regime. Scale build-up on the walls [Fig. 15(d)] can have similar, but reduced effect. This is detrimental in hydroentanglement applications where consistency between adjacent nozzles is extremely important for uniformity of the resulting fabric properties and must be prevented by stringent filtration of the process fluid. Moreover, it is essential that nozzles are regularly cleaned in an ultrasonic bath to ensure reliable results.

2. Manufacturing process and tolerances. The second factor affecting nozzle performance is the manufacturing process. Key tolerances were found to depend on geometry:

(a) in capillary nozzles, some edge roundness is unavoidable due to the manufacturing process;

(b) in cone-capillary nozzles, this problem is not faced, due to the presence of the cone, but the quality of the junction between the conical and capillary sections strongly affects the nozzle characteristics [Figs 15 (e) and (f)];

(c) in conical nozzles, control of the nozzle exit diameter to high accuracy appears to be more difficult;

(d) elliptical nozzles are not used in industrial applications, their production was more costly and yielded lower quality of the inlet edges, which were rougher in elliptical nozzles than in circular nozzles [Figs 15(a) and (b)];

(e) wear at the edge and wall of the nozzle generally results in edge rounding and rougher surface and larger diameters compared to the unused nozzle. The wear rate depends on the nozzle material, speed of flow, and the water hardness.

\section{CONCLUSIONS}

Our tests have shown that the characteristics of nozzles of $120-170 \mu \mathrm{m}$ at pressures $3-12 \mathrm{MPa}$ are governed by inertia and viscous forces and cavitation 
effects due to rapid local changes in pressure. This is similar in many respects to that of automotive nozzles researched previously. The dominant geometry effect is associated with different possible flow regimes near the inlet to the smallest nozzle cross-section: (a) attached flow for rounded and conical inlets with small cone angle; (b) separated flow or hydraulic flip for sharp inlets and high cone angles. Diameter changes between 120 and $170 \mu \mathrm{m}$ did not affect the discharge coefficient $C_{\mathrm{d}}$ of capillary nozzles. The behaviour of elliptic capillary nozzles is similar to those with circular cross-section, but was found to be strongly affected by manufacturing inaccuracies at large aspect ratio. A multihole nozzle arrangement causes a small increase to $C_{\mathrm{d}}$. The overall conclusion of this study is that manufacturing tolerances and surface roughness effects become critically important factors in determining flow characteristics of very small nozzles.

Finally, our results challenge common simplifying assumptions: $C_{\mathrm{d}}=C_{\mathrm{v}}$ and $C_{\mathrm{c}}=1$ for nozzles with attached flow and $C_{\mathrm{d}}=C_{\mathrm{c}}$ and $C_{\mathrm{v}}=1$ for nozzles operating post-hydraulic-flip $[\mathbf{7 , 8}$. The measurements of discharge, velocity, and contraction coefficients in conjunction with near-orifice visualizations have shown that the fluid mechanics is more complex. Frictional effects reduce as the supply pressure increases causing an increase in $C_{\mathrm{v}}$ and $C_{\mathrm{d}}$ for rounded inlets and low cone angles. For sharp inlets or conical nozzles with higher cone angles, the increase of $C_{\mathrm{v}}$ is offset by a larger reduction in the contraction coefficient $C_{\mathrm{c}}$ due to boundary layer thinning causing a net decrease in $C_{\mathrm{d}}$ for these geometries.

\section{ACKNOWLEDGEMENTS}

Part of this work was carried out under EPSRC contract no. gr/169749. The authors gratefully acknowledge the financial and in-kind support of Courtaulds Engineering Limited and Spunlace Technology Ltd. All imaging work was performed by Dr. G.K. Hargrave, whose contribution is gratefully acknowledged.

\section{REFERENCES}

1 Bergwerk, W. Flow pattern in diesel nozzle spray holes. Proc. Instn Mech. Engrs, 1959, 173(25), 655-660.

2 Reitz, R. D. and Bracco, F. V. Mechanism of atomization of a liquid jet. Phys. Fluids, 1982, 25(10), 1730-1742.

3 Wu, K.-J., Su, C.-C., Steinberger, R. L., Santavicca, D. A., and Bracco, F. V. Measurements of the spray angle of atomizing jets. Trans. ASME, J. Fluids Eng., 1983, 105, 406-413.

4 Arai, M., Shimizu, M., and Hiroyasu, H. Break-up length and spray formation mechanism of a high speed liquid jet. Proceedings of ICLASS-85, The Institute of Energy, London, England, 8-10 July 1985, $\mathrm{IB} / 4 / 1-\mathrm{IB} / 4 / 10$.

5 Arai, M., Shimizu, M., and Hiroyasu, H. Break-up length and spray formation mechanism of a high speed liquid jet. Proceedings of ICLASS-88, The Fuel Society, Sendai, Japan, 21-24 August 1988, pp. 177184, Paper A4.

6 Hiroyasu, H., Arai, M., and Shimizu, M. Break-up length of a liquid jet and internal flow in a nozzle. Proceedings of ICLASS-91, NIST, Gaithersburg, MD, USA, 15-18 July 1991, pp. 275-285, Paper 26.

7 Ohrn, T. R., Senser, D. W., and Lefebvre, A. H. Geometrical effects on discharge coefficients of plainorifice atomizers. At. Sprays, 1991, 1(2), 137-153.

8 Karasawa, T., Tanaka, M., Abe, K., Shiga, S., and Kurabayashi, T. Effect of nozzle configuration on the atomization of a steady spray. At. Sprays, 1992, 2, 411-426.

9 Fechter, T. Product innovations in high pressure hydroentangling systems. Proceedings of the International Nonwovens Conference INDA-TEC'99, 21-23 September 1999, Atlanta, GA, USA, Paper 10.0.

10 Ghassemieh, E., Acar, M., and Versteeg, H. K. Improvement of the efficiency of energy transfer in the hydroentanglement process. Compos. Sci. Technol., 2001, 61(12), 1681-1694.

11 Ghassemieh, E., Versteeg, H. K., and Acar, M. Effect of nozzle geometry on the flow characteristics of hydroentangling jets. Text. Res. J., 2003, 73(5), 444-450.

12 Begenir, A., Vahedi Tafreshi, H., and Pourdeyhimi, B. Effect of nozzle geometry on hydroentangling water jets: experimental observations. Text. Res. J., 2004, 74(2), 178-184.

13 Vahedi Tafreshi, H., Pourdeyhimi, B., Holmes, R., and Shiffler, D. Simulating and characterizing water flows inside hydroentangling orifices. Text. Res. J., 2003, 73(3), 256-264.

14 Vahedi Tafreshi, H. and Pourdeyhimi, B. Simulating the flow dynamics in hydroentangling nozzles: effect of cone angle and nozzle aspect ratio. Text. Res. J., 2003, 73(8), 700-704.

15 Vahedi Tafreshi, H. and Pourdeyhimi, B. Simulating cavitation and hydraulic flip inside hydroentangling nozzles. Text. Res. J., 2004, 74(4), 359-364.

16 Mansour, A. and Chigier, N. Effect of turbulence on the stability of liquid jets and the resulting droplet size distributions. At. Sprays, 1994, 4, 583-604.

17 Lin, S. P. and Reitz, R. D. Drop and spray formation from a liquid jet. Annu. Rev. Fluid Mech., 1998, 30, 85-105.

18 Soteriou, C., Andrews, R., and Smith, M. Direct injection diesel sprays and the effect of cavitation and hydraulic flip on atomization. SAE Paper 950080, 1995.

19 Chaves, H., Knapp, M., Kubitzek, A., Obermeier, F., and Schneider, T. Experimental study of cavitation in the nozzle hole of diesel injectors using transparent nozzles. SAE paper 950290, 1995.

20 Fox, T. A. and Stark, J. Characteristics of miniature short-tube orifice flows. Proc. Instn Mech. Engrs, Part C: J. Mechanical Engineering Science, 1989, 203, 351-358.

21 Fried, E. and Idelchik, I. E. Flow resistance-a design guide for engineers, 1989 (Taylor \& Francis, Philadelphia, PA). 
22 Schmidt, D. P., Rutland, C. J., and Corradini, M. L. $A$ numerical study of cavitating flow through various nozzle shapes. SAE paper 971597, 1997.

23 Wu, P.-K., Miranda, R. F., and Faeth, G. M. Effects of initial flow conditions on primary break-up of nonturbulent and turbulent round liquid jets. At. Sprays, 1995, 5, 175-196.

24 Hall, G. W. Analytical determination of the discharge characteristics of cylindrical-tube orifices. J. Mech. Eng. Sci., 1963, 5(1), 91-97.

25 Reitz, R. D. and Bracco, F. V. Ultra-high-speed filming of atomizing jets. Phys. Fluids, 1979, 22(6), 1054-1064.

26 Gurevich, M. I. Theory of jets of ideal fluids, 1965 (Academic Press, New York).

\section{APPENDIX}

\section{Notation}

$A_{\mathrm{N}} \quad$ nozzle area

$a$ major axis of elliptical nozzle $b \quad$ minor axis of elliptical nozzle

$C_{\mathrm{c}} \quad$ contraction coefficient

$C_{\mathrm{d}} \quad$ discharge coefficient

$C_{\mathrm{v}} \quad$ velocity coefficient

$D \quad$ nozzle diameter

$D_{\mathrm{e}} \quad$ equivalent diameter

$D_{\mathrm{h}} \quad$ hydraulic diameter

$F \quad$ impact force

$L \quad$ axial length of capillary section of nozzle

$L_{\mathrm{c}} \quad$ axial length of conical section of nozzle

$\dot{m} \quad$ mass flow rate

$P \quad$ supply pressure (gauge)

$\wp \quad$ perimeter

$r \quad$ edge radius

Re Reynolds number, $4 \dot{m} /(\pi D \mu)$

$V_{\mathrm{j}} \quad$ jet velocity

$\alpha \quad$ nozzle cone angle

$\mu \quad$ liquid viscosity

$\rho \quad$ liquid density 